\title{
Laboratory Experiments on the Effect of Microtopography on Soil-Water Movement: Spatial Variability in Wetting Front Movement
}

\author{
Leif Sande and Xuefeng Chu \\ Department of Civil Engineering, North Dakota State University, Dept 2470, P.O. Box 6050, Fargo, ND 58108-6050, USA \\ Correspondence should be addressed to Xuefeng Chu, xuefeng.chu@ndsu.edu \\ Received 6 September 2011; Accepted 2 December 2011 \\ Academic Editor: Alessandro Piccolo
}

Copyright (C) 2012 L. Sande and X. Chu. This is an open access article distributed under the Creative Commons Attribution License, which permits unrestricted use, distribution, and reproduction in any medium, provided the original work is properly cited.

The effect of microtopography on soil-water movement is a topic of interest for a range of disciplines, with experimental studies investigating the relationship between the two lacking. Laboratory experiments were conducted by simulating rainfall across packed soil surfaces to investigate the effect of microtopography on wetting front movement within experimental soil profiles. In small soil box experiments, the observed wetting fronts for soil profiles showed considerably deeper movement beneath a smooth surface than depressions for 12-60 min rainfalls. For large soil box experiments, the wetting front reached moisture sensors installed at 5 and $10 \mathrm{~cm}$ depths and corresponding to various rough and smooth surface features at significantly different times, with movement being most rapid beneath the smooth surface. Wetting front movement was "quicker" beneath surface peaks than depressions for the rough surface as attributed to $2 \mathrm{D} / 3 \mathrm{D}$ unsaturated flow. This study provides valuable experimentally based insight into the effect of microtopography on soil-water movement.

\section{Introduction}

Infiltration is controlled by a number of factors such as soil capillary suction, initial moisture content, hydraulic conductivity, and pore structure. For practical applications (such as unsaturated flow modeling), infiltration is generally considered homogeneous across a soil surface. In reality, infiltration rates often vary significantly and dynamically across a soil surface $[1,2]$. Infiltration characteristics also strongly influence subsequent water percolation through the vadose zone.

The factors that control spatial and temporal variations in infiltration and soil-water percolation can be divided into three categories: site characteristics, soil characteristics, meteorological characteristics [3]. Site characteristics include slope, microtopography, vegetative cover, grazing conditions, and subsurface conditions; soil characteristics include saturated and unsaturated hydraulic conductivity, degree of aggregation, bulk density, and the presence of macropores; and meteorological characteristics include rainfall intensity, duration, and spatial variations [3]. Soil moisture condition is an important site characteristic, which exerts a significant influence on water movement in soils [3-6].

Microtopography is a site characteristic that can affect spatial variations in infiltration and soil-water percolation directly and indirectly and is a research area in need of significantly more work [7]. Generally, increasing soil roughness will result in increased infiltration [8-10] and varying microtopography will result in varying infiltration rates [11]. Surface microtopography may affect spatial variations in infiltration through its influence on surface ponding. It is well accepted that a rougher surface has greater depression storage and surface ponding compared to a smooth surface [12-14]. Increased ponding depth will increase infiltration due to the inundation of more surface area and increased ponding head [11, 15-18].

Microtopography may also influence spatial variations in infiltration as attributed to its role in the development of surface sealing $[5,16,17,19]$. Structural seals form due to aggregate breakdown as a direct result of rainfall 
impact and generally are most prevalent on surface peaks, while sedimentary seals are associated with the deposition of sediments in surface depressions [17]. Structural seals generally have much higher hydraulic conductivities than sedimentary seals $[16,17]$. During a rainfall event, structural seal formation generally occurs earlier while sedimentary seals develop more slowly [17]. Seal formation may also be affected by surface ponding due to the protection from raindrop impact the ponded water surface provides to the soil surface.

The significant influence of microtopography on spatial variations in infiltration subsequently translates directly towards its considerable influence on soil-water percolation by its control over the location and amount of water entering the soil. Both matric and gravitational forces control water movement in the soil. 2D/3D trends in soil-water movement beneath a rough surface of peaks and depressions may include significant horizontal wetting front movement as attributed to strong matric relative to gravitational forces initially acting on water in soil, after which gravitational forces generally become predominant with time [20].

To the best of our knowledge, very limited experimental work has been conducted evaluating soil-water movement characteristics (e.g., wetting front movement) as affected by surface microtopography. The objective of this research is to investigate the effect of microtopography on soilwater movement, especially wetting front movement, by conducting a set of laboratory-scale, small and large soil box experiments under simulated rainfalls across both smooth and rough surfaces. Soil moisture data pertaining to different surface microtopographic features were collected and utilized to examine the spatial variability in wetting front movement and soil moisture content associated with different surface microtopographic characteristics.

\section{Methodology}

2.1. Experimental Soil Profile Packing Procedures. A set of laboratory-scale soil box experiments were conducted by packing soil into two different soil boxes (small and large). The $30 \times 30 \mathrm{~cm}$ small box was built with a wooden frame and clear plexiglass sides and was designed with the capability of packing soil to a uniform bulk density $\left(\rho_{b}\right)$ while incorporating a surface mold. A surface mold was created with the desired microtopography. The bottom of the soil box was removed and the mold was attached to the top of the empty soil box; the soil box was then rotated upside down and soil was packed uniformly in $2.5 \mathrm{~cm}$ layers to achieve a predetermined $\rho_{b}$ (based on the void volume and mass of soil); the bottom of the soil box was reattached and the soil box was rotated back to right side up, and the mold was removed. The resulting soil surface was an exact replication of the surface mold with a uniform $\rho_{b}$ throughout the soil profile pertaining to smooth areas, depressions, and peaks. One side of the soil box was removable so that the soil profile could be manually cut in order to evaluate the wetting front location within the soil profile corresponding to different surface microtopographic features.
For the large soil box experiments, a $100 \times 120 \mathrm{~cm}$ soil box was utilized. Sande et al. [21] detailed the soil box, a mold of desired surface microtopography, and the procedures for soil packing and surface creation. A key feature of the method is the capability to replicate rough soil surfaces while maintaining uniform $\rho_{b}$ throughout the soil profile, which was verified experimentally [21]. Additionally, the soil box incorporates a divider placed down the center of the box creating adjacent $60 \times 100 \mathrm{~cm}$ smooth and rough soil surfaces for each packed soil box to facilitate simultaneous side-by-side comparison of experiments for two distinct surface microtopographic conditions [21]. For the small soil box, the same soil packing method was applied as for the large soil box, with greater simplicity and the capability for better accuracy in the packing procedure due to the smaller scale. Thus, uniformity in bulk densities can be safely assumed.

For both small and large soil box experiments, a loamy sand (LS) soil $(80.3 \%, 14.6 \%$, and $5.1 \%$ sand, silt, and clay, resp.) was utilized. Four small soil box experiments were conducted with similar initial moisture contents $\left(\theta_{i}\right)$ ranging from 0.063 to $0.080 \mathrm{~cm}^{3} / \mathrm{cm}^{3}$, while two large soil box experiments were conducted using two different $\theta_{i}$ values of 0.144 and $0.073 \mathrm{~cm}^{3} / \mathrm{cm}^{3}$. The $\theta_{i}$ values were determined experimentally based on the gravimetric moisture content and $\rho_{b}$. Basic experimental information and major soil property parameters are shown in Table 1 .

2.2. Surface Topography. For both the small and large soil boxes, surface microtopography was obtained using an instantaneous-profile laser scanner [22,23]. The small soil box surface consisted of two depressions and an adjacent smooth surface (Figure 1). For the large soil box surface, the aforementioned smooth and rough soil surfaces are shown in Figure 2. More design criteria for the rough soil surface of the large soil box can be found in [21].

2.3. Norton Style Rainfall Simulator. A Norton-style rainfall simulator utilizing four oscillating VeeJet nozzles was used to simulate rainfall across soil surfaces in this study. The simulator has been proven to closely replicate natural rainfall characteristics including raindrop size, terminal velocity, energy, and spatial distribution [24, 25]. The simulator is designed to simulate rainfall across a $1.50 \times 4.50 \mathrm{~m}$ surface area at the design height of $2.44 \mathrm{~m}$ with programmable rainfall intensities ranging from 0.97 to $10.42 \mathrm{~cm} / \mathrm{hr}$ by controlling the nozzle sweep frequency. The rainfall simulator was calibrated and actual spatial distributions of the simulated rainfall were determined. Then, the areas with relatively uniform distributions of rainfall intensities were selected for the small and large soil box experiments. The average rainfall intensities for the small and large soil box experiments were 3.80 and $5.79 \mathrm{~cm} / \mathrm{hr}$, respectively (Table 1 ).

2.4. Soil Moisture. For the small soil box experiments, the visible wetting front within the soil profile was recorded at the conclusion of rainfall events by cutting the soil profile and measuring the depth from the surface to the observed wetting 
TABle 1: Basic Experimental Information and Soil Properties.

\begin{tabular}{|c|c|c|c|c|c|c|c|c|}
\hline $\operatorname{Exp}^{1}$ & Soil $^{2}$ & $\begin{array}{c}\text { Surface } \\
\text { description }\end{array}$ & $\begin{array}{c}\text { Surface } \\
\text { size }(\mathrm{s})(\mathrm{cm})\end{array}$ & $\begin{array}{c}\theta_{i}^{4} \\
\left(\mathrm{~cm}^{3} / \mathrm{cm}^{3}\right)\end{array}$ & $\rho_{b}^{5}\left(\mathrm{~kg} / \mathrm{m}^{3}\right)$ & $r^{6}(\mathrm{~cm} / \mathrm{hr})$ & $\begin{array}{c}\text { Surface } \\
\text { slope (\%) }\end{array}$ & $\begin{array}{c}\text { Duration } \\
\text { (min) }\end{array}$ \\
\hline S1 & LS & Combined R \& S & $30 \times 30$ & 0.063 & 1,400 & 3.80 & 0 & 12 \\
\hline S2 & LS & Combined R \& S & $30 \times 30$ & 0.059 & 1,400 & 3.80 & 0 & 20 \\
\hline S3 & LS & Combined R \& S & $30 \times 30$ & 0.080 & 1,400 & 3.80 & 0 & 40 \\
\hline S4 & LS & Combined R \& S & $30 \times 30$ & 0.064 & 1,400 & 3.80 & 0 & 60 \\
\hline L5 & LS & Separate R \& S & $60 \times 100$ & 0.144 & 1,400 & 5.79 & 7 & 78 \\
\hline L6 & LS & Separate R \& S & $60 \times 100$ & 0.073 & 1,400 & 5.79 & 7 & 120 \\
\hline
\end{tabular}

${ }^{1} \mathrm{~S}$ is the small soil box $(30 \times 30 \mathrm{~cm})$ and $\mathrm{L}$ is the large soil box $(120 \times 100 \mathrm{~cm})$.

${ }^{2} \mathrm{LS}$ is the loamy sand soil.

${ }^{3} \mathrm{R}$ signifies rough surface features and $\mathrm{S}$ signifies smooth surface features.

${ }^{4} \theta_{i}$ is the initial moisture content.

${ }^{5} \rho_{b}$ is the bulk density.

${ }^{6} r$ is the rainfall intensity.

front. The soil profile was manually cut at two locations (Figure 1) following the simulated rainfall. The depth of the wetting front was measured beneath the three surface features shown in Figure 1: the large depression, the small depression, and the smooth areas (including smooth area no. 1 and no. 2 in Figure 1). Four small soil box experiments with similar $\theta_{i}$ values and different durations were conducted so that wetting front characteristics pertaining to different surface feature could be collected for a range of different rainfall durations (i.e., 12-60 min, Table 1).

For the large soil box experiments, soil moisture data were collected utilizing moisture sensors installed in soil profiles to investigate the effect of microtopography on soil-water movement. Soil moisture was measured in each experiment at $1 \mathrm{~min}$ intervals using Decagon EC-5 moisture sensors installed parallel to the soil surface at depths of 5 and $10 \mathrm{~cm}$ at various locations within the soil profiles beneath both the smooth and rough surfaces (Figure 2). In Figure 2, sensor notations of 5 and 10 refer to 5 and $10 \mathrm{~cm}$ depths. For the rough surface, two moisture sensors (A5 and A10) were placed beneath a surface peak while the remaining four sensors were located beneath two major depressions (Figure 2(a)).

2.5. Experimental Procedures and Measurements. For both small and large soil box experiments, soil was packed into the boxes with soil, surface(s) were scanned using the laser scanner, the soil boxes were placed beneath the rainfall simulator, and rainfall was then simulated across the surface(s). For the small soil box experiments, rainfall was simulated across the soil surfaces for predetermined periods of time ranging from 12 to $60 \mathrm{~min}$ (Table 1). Following the termination of rainfall, one side of the soil box was immediately removed. The soil profile was subsequently cut and wetting front depths were measured at the two locations shown in Figure 1 without delay to reduce the effects as a result of continued soil moisture redistribution to the extent practically possible.

For the large soil box experiments, rainfall was simulated across the soil surfaces until both rough and smooth surfaces were fully ponded. The fully ponded status was visually determined as the time when the entire areas of both the rough and smooth surfaces were fully contributing to runoff flow (i.e., for both the smooth and rough surfaces, surface runoff water was visible across the entirety of both surface areas, and additionally for the rough surface, all depressions were completely filled).

During the experiments, data including wetting front, outlet flow, and surface ponding status were collected. For soil moisture sensor data collected, time for the advancing wetting front to reach each moisture sensor $\left(t_{\text {wet }}\right)$ was determined as the time when the first significant step increase in moisture content $(\theta)$ from $\theta_{i}$ was observed. As a verification of this method, sensor $t_{\text {wet }}$ values were also compared with the observed wetting front data, for which it was verified that the sensor $t_{\text {wet }}$ consistently represented a time slightly before arrival of the actual observed wetting front at the depth of the moisture sensors. This can be primarily attributed to the zone of influence and sensitivity of the moisture sensor. The concentration for this study, however, is on examining the differences in the $t_{\text {wet }}$ values between the rough and smooth surfaces. Thus, consistency in the sensor $t_{\text {wet }}$ values was most important as opposed to exact $t_{\text {wet }}$ and $\theta$ values.

\section{Results and Discussion}

\subsection{Wetting Front Movement as Affected by Surface Microtopography}

3.1.1. Small Soil Box Experiments. Final wetting front depths at the three surface locations (i.e., large and small depressions and smooth areas) for the four small soil box experiments are shown in Table 2. For all experiments, the final wetting front depths beneath the smooth areas were deeper than those in both the large and small depressions. Compared with the large depression, the final wetting front depths were 1.25$1.75 \mathrm{~cm}$ deeper beneath the smooth area (average of smooth area no. 1 and no. 2 as aforementioned, Figure 1 and Table 2). Similar results (i.e., deeper wetting front depth beneath the smooth area) were observed for the small depression compared with the smooth area (average of smooth area no. 


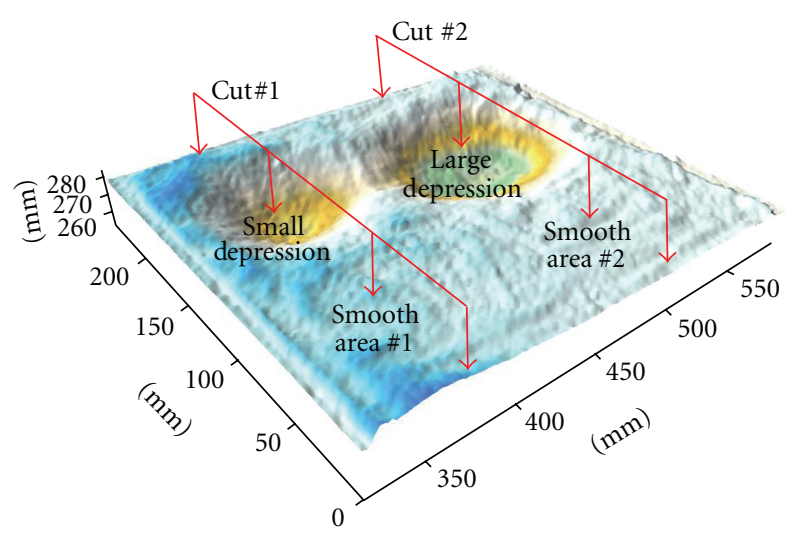

FIGURE 1: Small soil box surface microtopography and soil profile cutting locations.

TABLE 2: Small soil box final cut wetting front depths.

\begin{tabular}{lccc}
\hline $\operatorname{Exp}^{1}$ & $\begin{array}{c}\text { Large } \\
\text { depression }\end{array}$ & $\begin{array}{c}\text { Surface location } \\
\text { Small } \\
\text { depression }\end{array}$ & $\begin{array}{c}\text { Smooth } \\
\text { area }^{2}\end{array}$ \\
\hline S1 WF $(\mathrm{cm})$ & 3.00 & 3.00 & 4.50 \\
S2 WF $(\mathrm{cm})$ & 5.00 & 4.75 & 5.75 \\
S3 WF $(\mathrm{cm})$ & 8.50 & 9.00 & 9.75 \\
S4 WF $(\mathrm{cm})$ & 13.00 & 13.50 & 14.75 \\
\hline
\end{tabular}

${ }^{1}$ S1-S4 refer to Exp. S1-S4, respectively; WF is the final cut wetting front depth relative to the surface.

${ }^{2}$ Smooth area wetting front depths are the average of smooth areas no. 1 and no. 2 (Figure 1).

1 and no. 2, Figure 1). The final wetting front depths beneath the large and small depressions were similar for shortduration experiments (i.e., Exp S1 and S2, Table 2). However, slightly deeper final wetting fronts were observed beneath the smaller depression for longer-duration experiments (i.e., Exp S3 and S4, Table 2).

Overall results from the small soil box experiments clearly show increased wetting front movement depths relative to the surface associated with the smooth area compared with microtopographic depressions. In addition, the discrepancy in final wetting front depths between the smooth area and both depressions was very similar across all four experiment durations of 12-60 min. These results show that even for the longest experiment duration utilized (i.e., $60 \mathrm{~min}$ ), the effect of microtopography on wetting front movement is still very evident.

3.1.2. Large Soil Box Experiments. Moisture sensor data for the large soil box experiments Exp L5 and L6 (Table 1) were collected and are shown in Figures 3 and 4. Compared with the smooth surface, high variability in soil-water movement characteristics can be observed for the rough surface for Exp L5 and L6 (Figures 3 and 4). Based on the sensorrecorded soil moisture data for shallow and deep depths of both the smooth and rough surfaces (Figure 2), $t_{\text {wet }}$ values were determined for all sensors and are shown in Table 3.
TABLE 3: Large soil box wetting front times $\left(t_{\mathrm{wet}}\right)$.

\begin{tabular}{lcc}
\hline Sensor & Exp. L5 ${ }^{1} t_{\text {wet }}^{3}(\mathrm{~min})$ & Exp. L6 $^{2} t_{\text {wet }}^{3}(\mathrm{~min})$ \\
\hline A5 & 11 & 14 \\
B5 & 12 & 12 \\
C5 & 13 & 18 \\
D5 & 9 & 10 \\
E5 & 10 & 11 \\
F5 & 10 & 11 \\
A10 & 27 & 27 \\
B10 & 28 & 33 \\
C10 & 34 & 43 \\
D10 & 27 & 28 \\
E10 & 24 & 29 \\
F10 & 25 & 27 \\
\hline
\end{tabular}

${ }^{1}$ L5 refers to Exp. L5 with $\theta_{i}=0.144 \mathrm{~cm}^{3} / \mathrm{cm}^{3}$.

${ }^{2}$ L6 refers to Exp. L6 with $\theta_{i}=0.073 \mathrm{~cm}^{3} / \mathrm{cm}^{3}$.

${ }^{3} t_{\text {wet }}$ is the time for the wetting front to reach the sensor.

The $t_{\text {wet }}$ values for the smooth surface were in very close agreement with each other across the three shallow and deep moisture sensors for both Exp L5 and L6 (Table 3), which shows the uniformity in soil-water movement beneath the smooth surface. For the rough surface, however, the variability in $t_{\text {wet }}$ values across the sensors was large compared with the smooth surface values. Particularly for the deep moisture sensors of the rough surface, the $t_{\text {wet }}$ values ranged from 27 to $34 \mathrm{~min}$ for Exp L5 and from 27 to $43 \mathrm{~min}$ for Exp L6 (Table 3).

For both Exp L5 and L6, sensors A5 and A10 located beneath the peak on the rough surface profile (Figure 2(a)) had the shortest $t_{\text {wet }}$ values of all rough surface moisture sensors in almost all cases (Table 3). Sensors B5 and B10, located beneath the large depression of the rough surface (Figure 2(a)), had $t_{\text {wet }}$ values close to those of sensors A5 and A10 although the $t_{\text {wet }}$ values for A5 and A10 were slightly shorter for almost all cases (Table 3 ). Sensors C5 and $\mathrm{C} 10$ located beneath the small downstream depression (Figure 2(a)), however, had $t_{\text {wet }}$ values much longer than those of all other sensors across the rough surface (Table 3 ).

Compared with smooth surface sensor $t_{\text {wet }}$ values, all rough surface sensor $t_{\text {wet }}$ values pertaining to both peaks and depressions were greater for both Exp L5 and L6. However, sensors A5 and A10 pertaining to the surface peak had $t_{\text {wet }}$ values and the subsequent wetting front movement characteristics that were very close to those observed beneath the smooth surface. The rough surface sensors located beneath the surface depressions (particularly sensors C5 and C10) had $t_{\text {wet }}$ values (and the subsequent wetting front movement characteristics) which were consistently larger than those observed beneath the smooth surface. This general finding of increased wetting front movement beneath high-elevation peaks was similar to that observed in the small soil box experiments. Also similar to the small soil box experiments, the effect of microtopography on soil-water movement was very evident for longer-duration experiments. As the wetting 


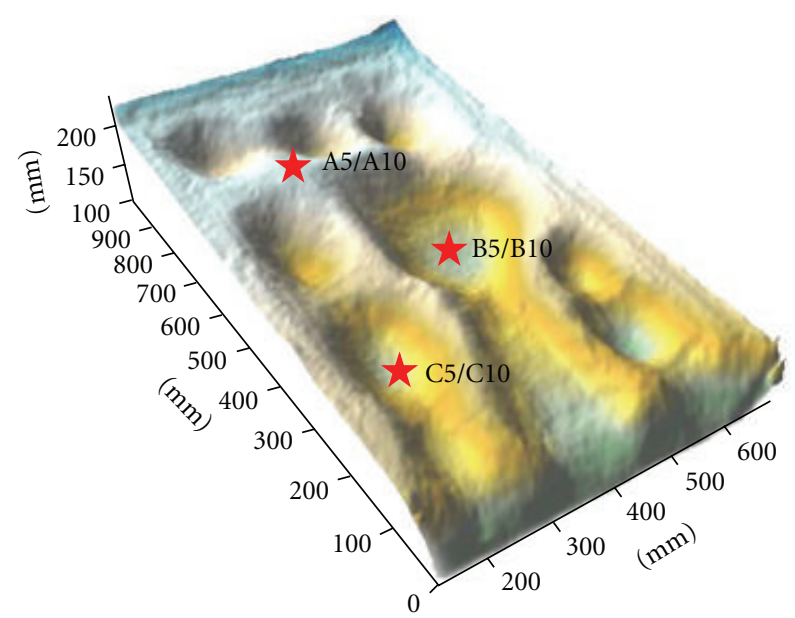

(a)

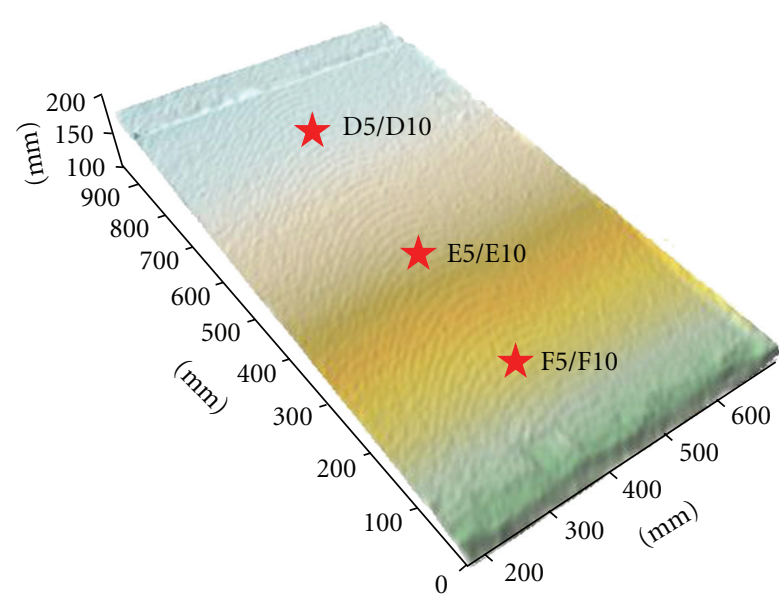

(b)

FIGURE 2: Large soil box surface microtopography and moisture sensor locations at depths of 5 and $10 \mathrm{~cm}$ for both (a) rough and (b) smooth surfaces.

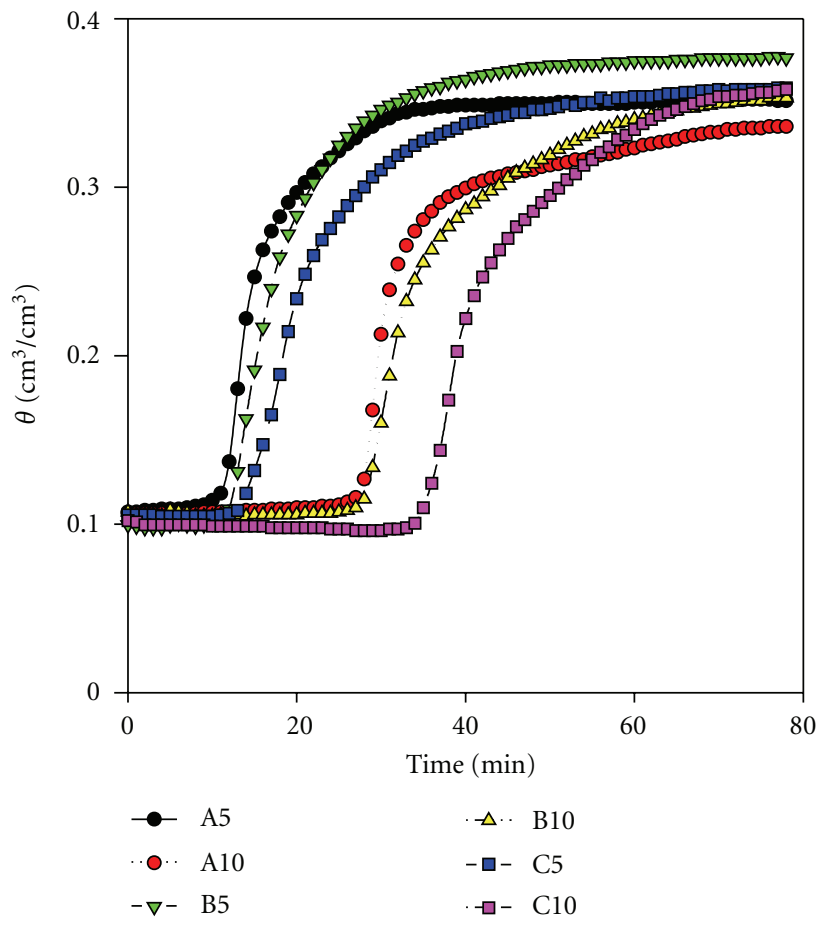

(a)

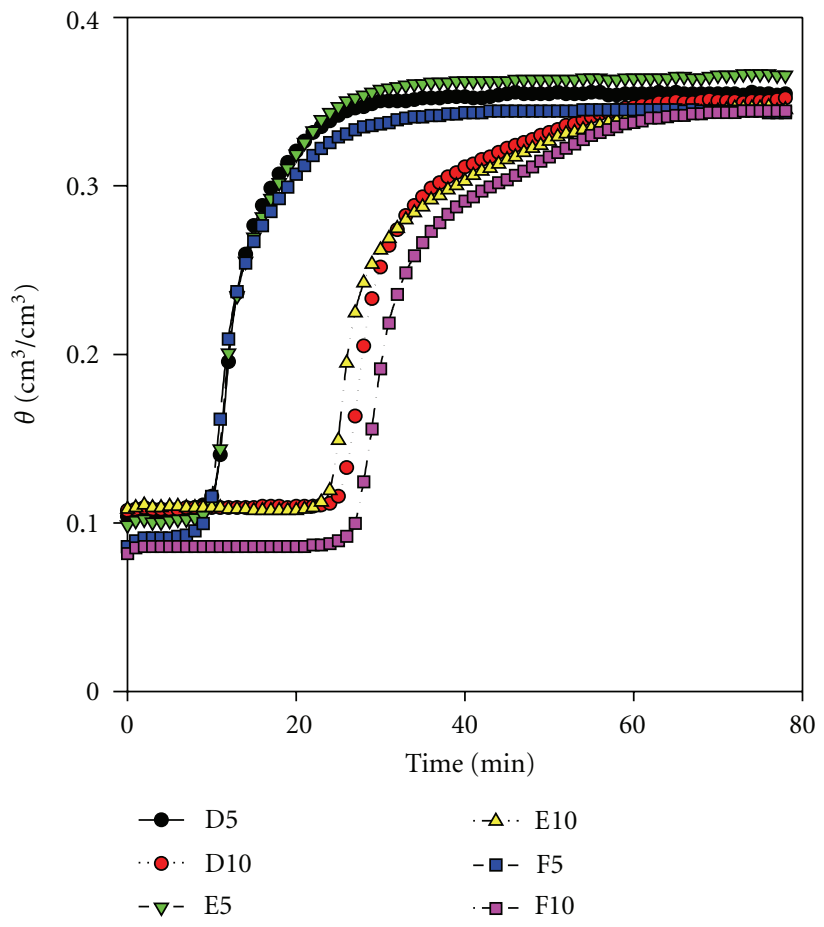

(b)

FIGURE 3: Large soil box moisture sensor data for initial water content $\theta_{i}=0.144 \mathrm{~cm}^{3} / \mathrm{cm}^{3}$ for (a) rough and (b) smooth surfaces.

front moved deeper in the soil profile, the discrepancy between deep moisture sensor $t_{\text {wet }}$ values increased. That is, there was increasing variability in $t_{\text {wet }}$ values across sensors pertaining to different surface microtopographic features as the wetting front moved deeper in the soil profile.

Pertaining to the effect of $\theta_{i}$ on wetting front movement for Exp L5 and L6, a clear trend was evident. For both the smooth/rough and shallow/deep moisture sensors in the two experiments, $t_{\text {wet }}$ values were markedly shorter for Exp L5 $\left(\theta_{i}=0.144 \mathrm{~cm}^{3} / \mathrm{cm}^{3}\right)$ compared with Exp L6 $\left(\theta_{i}\right.$ $\left.=0.073 \mathrm{~cm}^{3} / \mathrm{cm}^{3}\right)$. This showed more rapid wetting front movement associated with higher $\theta_{i}$, which agrees with the known relationship between unsaturated hydraulic conductivity $(K)$ and $\theta_{i}$ (i.e., positive relationship of increasing $K$ with increasing $\theta_{i}[20]$ ), and further conveys the strong influence of moisture content on wetting front movement. 


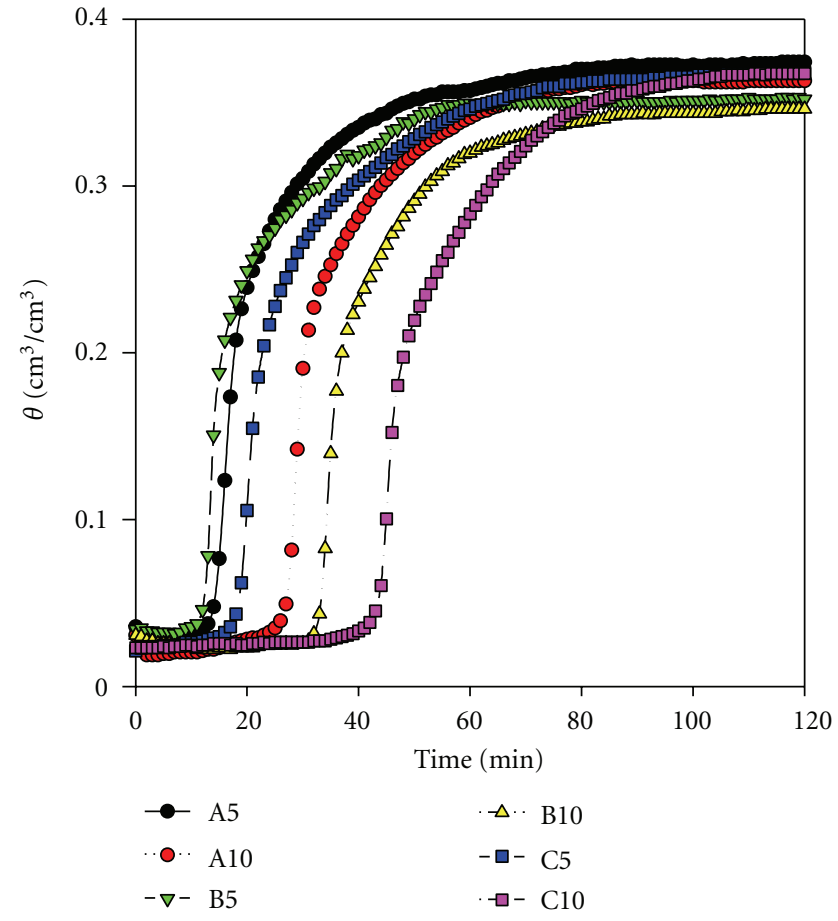

(a)

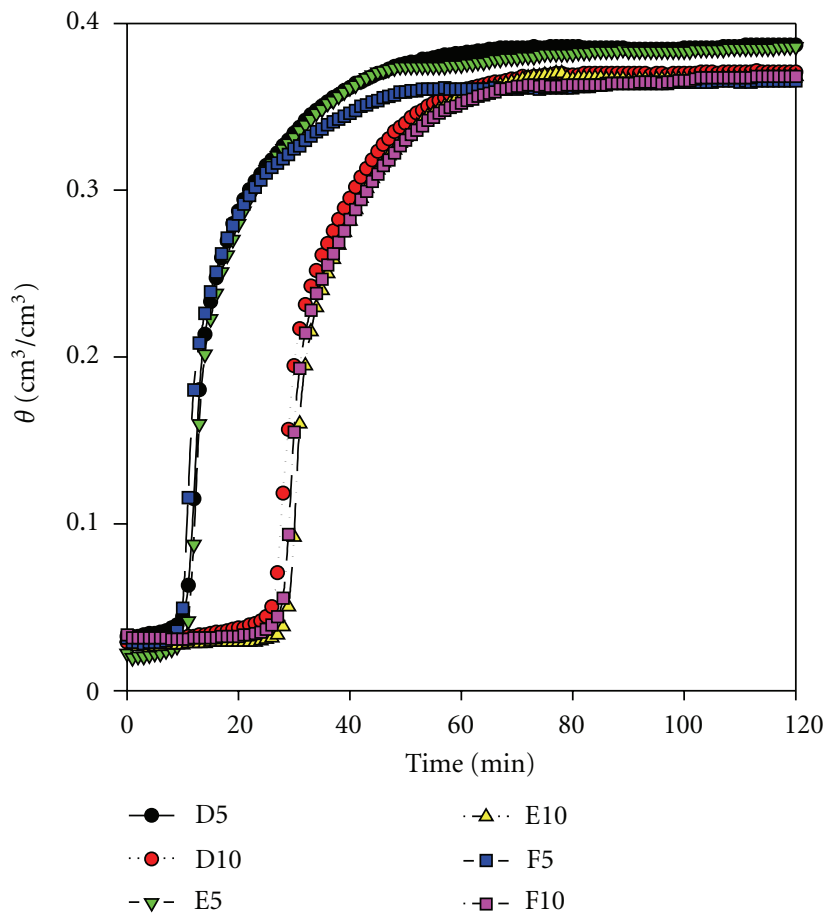

(b)

Figure 4: Large soil box moisture sensor data for initial water content $\theta_{i}=0.073 \mathrm{~cm}^{3} / \mathrm{cm}^{3}$ for (a) rough and (b) smooth surfaces.

3.2. Further Discussions on the Relationship of Microtopography and Soil-Water Movement. Several potential effects of microtopography on soil-water movement characteristics may contribute to the findings observed in this study for both the small and large soil box experiments, particularly in wetting front movement characteristics. One effect of microtopography on soil-water movement, which may have contributed to increased wetting front movement relative to the smooth surface (small and large soil box) and the surface peak (large soil box), can be attributed to the matric and gravitational forces acting on soil-water movement. For uniform rainfall on a smooth surface, soil-water movement is primarily along the vertical direction as the wetting front moves downwards with both gravitational and matric (due to the dry soil located directly beneath the advancing wetting front) forces acting in the vertical direction. Beneath a rough surface of peaks and depressions, however, matric relative to gravitational forces may be particularly strong in horizontal directions initially, as attributed to the dry soil located in a radial direction both towards the "center" of peaks and outwards surrounding the boundaries of depressions. These characteristics may lead themselves towards a tendency of "converging" and "diverging" wetting front patterns beneath peaks and depressions, respectively. In addition, for a surface of only depressions and smooth areas (i.e., small soil box surface), the depressions may contribute to increased wetting front movement beneath the adjacent smooth areas as attributed to the aforementioned reasons. Together, these trends and 2D/3D unsaturated flow likely contributed to the increased wetting front movement relative to the surface for the smooth surface for both the small and large soil box experiments as well as the lower $t_{\text {wet }}$ values for the large soil box experiments pertaining to the peak compared with depressions for the rough surfaces.

Another possible effect of microtopography on soil-water movement characteristics in this study may be attributed to its influence on surface ponding and resulting preferential infiltration. As no surface ponding was observed in the small soil box experiments, discussion on this effect will focus on the large soil box experiments. For Exp L6, no surface ponding was observed on either the rough or smooth surface before the wetting front reached any sensors. For Exp L5, however, surface ponding occurred before the wetting front reached the deep sensors for both the smooth and rough surfaces. In particular, for sensors B5 and B10 of the rough surface (Figure 2(a)), surface ponding at that location was first observed at $17 \mathrm{~min}$, which may have contributed to the shorter $t_{\mathrm{wet}}$ values for the deep sensor (B10). Still, $t_{\mathrm{wet}}$ values at that location (B10) were high compared with those pertaining to both the peak (A10) and smooth surface (D10, E10, and F10) sensors (Table 3), even with the additional effect of surface ponding.

The wetting front movement trends observed in the small and large soil box experiments also may be attributed to the potential effect of microtopography on seal formation. Depressions are generally associated with the formation of lower hydraulic conductivity sedimentary seal formation due to the accumulation of sediments, while peaks and smooth areas are associated with the formation of higher hydraulic conductivity structural seal formation due to 
raindrop impact. It is possible, for both small and large soil box experiments, that the trend of decreased wetting front movement relative to the surface beneath depressions may be related to seal formation. However, this issue is out of the focus of this experimental study.

\section{Conclusions}

Laboratory-scale, small and large soil box experiments were conducted to investigate the effect of surface microtopography on infiltration and soil-water movement. Results from both the small and large soil box experiments showed considerably increased wetting front movement along higher peaks or smooth surfaces/plateaus compared with adjacent lower depressions, which can be attributed to 2D/3D unsaturated flow induced by variations in surface microtopography. That is, wetting front movement relative to the surface was "faster" pertaining to a surface peak than its adjacent depression(s). Considerable variability in wetting front movement beneath the rough surface as influenced by surface microtopography was also reflected in the high variability in wetting front travel time $t_{\text {wet }}$ values across the moisture sensors, while wetting front movement beneath the adjacent smooth surface was very uniform, again as reflected in $t_{\text {wet }}$ values across the moisture sensors of the smooth surface. For both small and large soil box experiments, the effect of microtopography on wetting front movement remained very evident even for longer-duration rainfalls and deeper soil-water movement. In addition, a relationship between $\theta_{i}$ and wetting front movement (i.e., more rapid wetting front movement for higher $\theta_{i}$ ) was observed in the large soil box experiments.

The findings of this study have potential implications for agricultural practices (particularly irrigation and surface runoff), solute transport in the vadose zone (particularly for shallow percolation), flooding (both timing and peak flow), and a range of other related areas. Further experimental studies are underway to address the effects of surface microtopography on infiltration and soil-water movement under varying conditions, in terms of spatial scales, surface roughness, soil types, initial moisture contents, and rainfall patterns. In addition, comparison of modeling of $1 \mathrm{D} / 2 \mathrm{D} / 3 \mathrm{D}$ unsaturated flow under influence of surface microtopography against experimental results will definitely improve our understanding of the underlying processes and mechanisms.

\section{Acknowledgments}

This paper is based upon the work supported by the National Science Foundation under Grant no. EAR-0907588. The authors would like to thank Dan Bogart, Yaping Chi, Jun Yang, and Shravan Avadhuta for their help during the experimental work.

\section{References}

[1] A. S. Tricker, "Spatial and temporal patterns of infiltration," Journal of Hydrology, vol. 49, no. 3-4, pp. 261-277, 1981.

[2] M. Sullivan, J. J. Warwick, and S. W. Tyler, "Quantifying and delineating spatial variations of surface infiltration in a small watershed," Journal of Hydrology, vol. 181, no. 1-4, pp. 149168, 1996.

[3] B. E. Haggard, P. A. Moore Jr., and K. R. Brye, "Effect of slope on runoff from a small variable slope box-plot," Journal of Environmental Hydrology, vol. 13, no. 25, pp. 1-8, 2005.

[4] Y. Le Bissonnais, B. Renaux, and H. Delouche, "Interactions between soil properties and moisture content in crust formation, runoff and interrill erosion from tilled loess soils," Catena, vol. 25, no. 1-4, pp. 33-46, 1995.

[5] M. K. Magunda, W. E. Larson, D. R. Linden, and E. A. Nater, "Changes in microrelief and their effects on infiltration and erosion during simulated rainfall," Soil Technology, vol. 10, no. 1, pp. 57-67, 1997.

[6] L. Wei, B. Zhang, and M. Wang, "Effects of antecedent soil moisture on runoff and soil erosion in alley cropping systems," Agricultural Water Management, vol. 94, no. 1-3, pp. 54-62, 2007.

[7] G. Govers, I. Takken, and K. Helming, "Soil roughness and overland flow," Agronomie, vol. 20, no. 2, pp. 131-146, 2000.

[8] R. E. Burwell and W. E. Larson, "Infiltration as influenced by tillage-induced random roughness and pore space," Proceedings of the Soil Science Society of America, vol. 33, pp. 449-452, 1969.

[9] K. Helming, M. J. M. Römkens, and S. N. Prasad, "Surface roughness related processes of runoff and soil loss: a flume study," Soil Science Society of America Journal, vol. 62, no. 1, pp. 243-250, 1998.

[10] J. A. Gómez and M. A. Nearing, "Runoff and sediment losses from rough and smooth soil surfaces in a laboratory experiment," Catena, vol. 59, no. 3, pp. 253-266, 2005.

[11] T. Dunne, W. Zhang, and B. F. Aubry, "Effects of rainfall, vegetation, and microtopography on infiltration and runoff," Water Resources Research, vol. 27, no. 9, pp. 2271-2285, 1991.

[12] J. K. Mitchell and B. A. Jones, "Micro-relief surface depression storage: analysis of models to describe the depth-storage function," Water Resources Bulletin, vol. 12, no. 6, pp. 12051222, 1976.

[13] C. A. Onstad, "Depressional storage on tilled soil surfaces," Transactions of the American Society of Agricultural Engineers, vol. 27, no. 3, pp. 729-732, 1984.

[14] F. Darboux, P. Davy, C. Gascuel-Odoux, and C. Huang, "Evolution of soil surface roughness and flowpath connectivity in overland flow experiments," Catena, vol. 46, no. 2-3, pp. 125139, 2002.

[15] D. M. Fox, R. B. Bryan, and A. G. Price, "The influence of slope angle on final infiltration rate for interrill, conditions," Geoderma, vol. 80, no. 1-2, pp. 181-194, 1997.

[16] D. M. Fox, Y. Le Bissonnais, and A. Bruand, "The effect of ponding depth on infiltration in a crusted surface depression," Catena, vol. 32, no. 2, pp. 87-100, 1998.

[17] D. M. Fox, Y. Le Bissonnais, and P. Quétin, "The implications of spatial variability in surface seal hydraulic resistance for infiltration in a mound and depression microtopography," Catena, vol. 32, no. 2, pp. 101-114, 1998.

[18] S. Assouline and M. Ben-Hur, "Effects of rainfall intensity and slope gradient on the dynamics of interrill erosion during soil surface sealing," Catena, vol. 66, no. 3, pp. 211-220, 2006.

[19] S. Assouline, "Rainfall-induced soil surface sealing: a critical review of observations, conceptual models, and solutions," Vadose Zone Journal, vol. 3, no. 2, pp. 570-591, 2004.

[20] D. Hillel, Environmental Soil Physics, Academic Press, San Diego, Calif, USA, 1998.

[21] L. Sande, X. Chu, and T. DeSutter, "A new method for replicating complex microtopographic surfaces in laboratory 
soil box experiments," Applied Engineering in Agriculture, vol. 27, no. 4, pp. 615-620, 2011.

[22] C.-H. Huang and J. M. Bradford, "Potable laser scanner for measuring soil surface roughness," Soil Science Society of America Journal, vol. 54, no. 5, pp. 1402-1406, 1990.

[23] F. Darboux and C. H. Huang, "An instantaneous-profile laser scanner to measure soil surface microtopography," Soil Science Society of America Journal, vol. 67, no. 1, pp. 92-99, 2003.

[24] L. D. Meyer and W. C. Harmon, "Multiple-intensity rainfall simulator for erosion research on row sideslopes," Transactions American Society of Agricultural Engineers, vol. 22, no. 1, pp. 100-103, 1979.

[25] L. D. Meyer, "Rainfall simulators for soil erosion research," in Soil Erosion Research Methods, R. Lal, Ed., CRC Press, 2nd edition, 1994. 

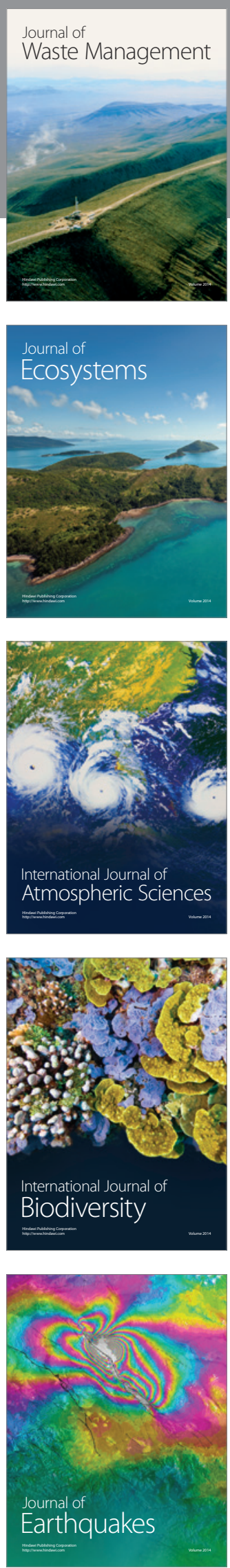
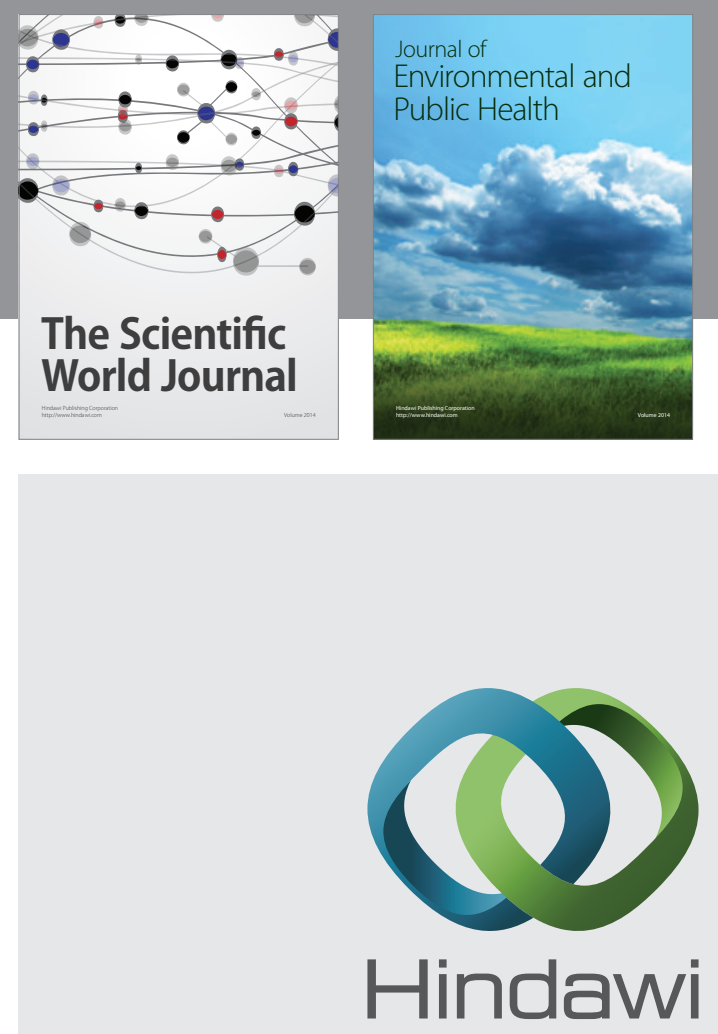

Submit your manuscripts at

http://www.hindawi.com
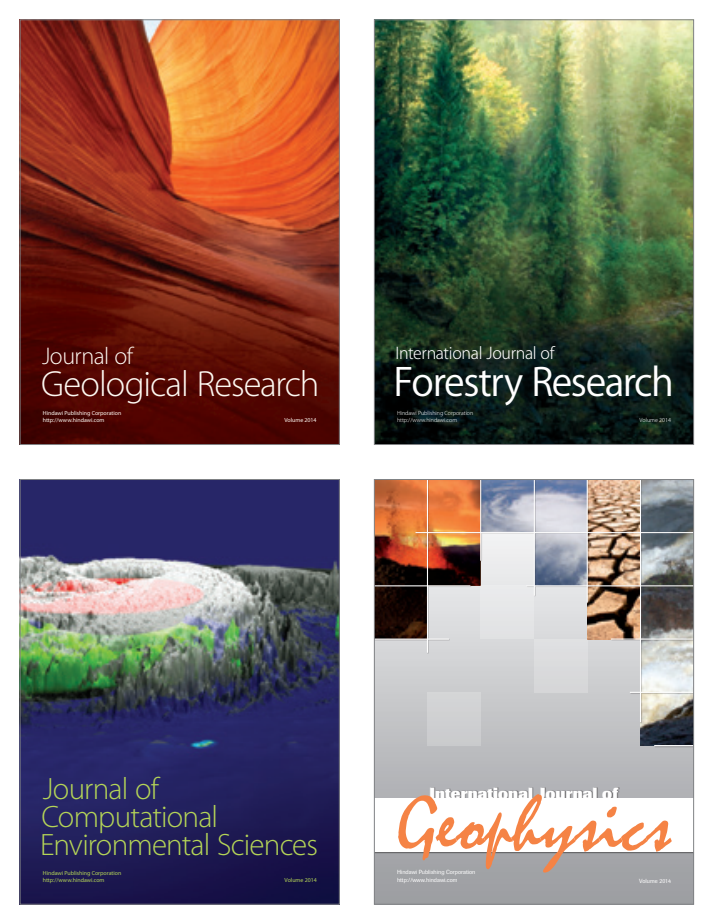
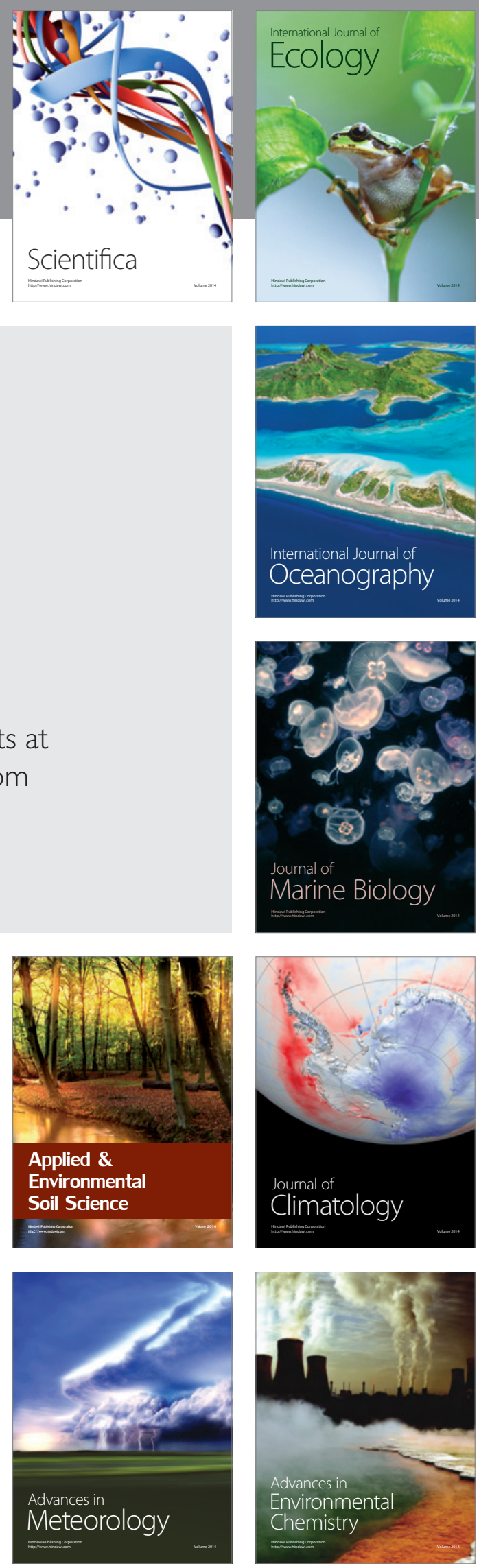